\title{
An exploration of the accounting profession - The stream of mobile devices
}

\author{
Victoria Stanciu ${ }^{a, 1}$ and Mirela Gheorghe \\ ${ }^{a}$ The Bucharest University of Economic Studies, Romania
}

\begin{abstract}
A bstract: Facing the digital era challenge, the accounting profession is implied in its renewal process a i ming at responding in an adequate manner to the companies' and society's continuous changing requirements. The paper emphasizes the impact of the information technology on the accounting profession and signals the positive impact and also the concerns brought by mobile devices in the accountants' work and training. In this context, the authors performed a survey ai ming to understand the accounting students' perception in regard with IT impact over the accounting profession and the usefulness of mobile devices. The study's findings provide important insights on the mobile devices use in the accounting work and how the teaching process can help students acquire IT skills and awareness on the professional use of mobile devices. The paper contributes to the research on the accounting developments in the digital era demonstrating the benefit of new technologies' implementation and integration of the mobile devices. The Romanian as well as the south-eastern European scientific literature are scarce in regard with mobile use in the accounting profession. In this regard the authors' research provide significant insights aiming at motivate and stimulate the mobile devices use in the accounting profession and in the academic and long life accounting trai ning.
\end{abstract}

Keywords: Accounting profession, information technology, mobile devices, $m$ learning.

J E L codes: $M 41, A 2,033$

${ }^{1}$ Corresponding author: Professor Victoria Stanciu, Department of Accounting and Management Information Systems, Bucharest University of Economic Studies; Piata Romana nr. 6, 010374 Bucharest; tel. (+40) 213191900 (382); email addresses: victoria.stanciu@cig.asero. 


\section{Introduction}

Aiming at ensuring business increase and profitability for their companies, managers adopted new business models and new business approaches. A significant role in all these changes is played by information technology that has substantial changed the way we are doing business today and has fundamental ly change the decision making process and reshaped many professional areas. The companies are operating in an intelligent economy that produces huge streams of data impacting the business and decision making process. The changes induced by big data, cloud computing, mobile and intelligent devices and not lastly social platforms, just to mention some information technologies "on the wave" are significantly impacting the accounting profession. ThelT environments, in which the companies are running the businesses and the accountant professionals are performing theirs daily work, redefine the professional profile of the accountants. The accounting professionals have to face the new challenges generated by digital services, artificial intelligence, cybercrime etc. The properly use of all new technologies brings huge challenges for the profession and reshapes the professional profile of the accountant enlarging the capabilities and skills to be achieved at individual level.

The accounting function acquires an important and critical role inside the company and the accounting profession is exposed to a continuous pressure in regard with its ability to permanently respond to the shareholders' requests. The classical role of ensuring the accounting data processing and providing internal and external reporting is changing, the accountants being "left for more strategic roles" (Faye, 2013). It is expected that more time to be allocated to the data analysis aiming at emphasize the economic and financial trends of the company, to identify options for the decision making process, better control the risks and, not lastly, budgeting and planning.

The unprecedented impact of the IT stream over the accounting profession raises new challenges and expectations for the profession. The complex information systems ensuring data processing, the change of the accounting data flows and processes (as for example ERP systems and cloud computing) require new IT and control skills. Data management and information security becomean important issue for the accounting professionals. The new IT solutions implemented in the companies as well as the computing based solutions for the accounting professionals change the environment in which the accounting professional is working, his way of thinking and practice and, is providing also important advantages - ensuring accuracy, effectiveness and efficiency.

The auditors fel at their turn the IT impact. The auditing procedures and objectives register changes as a result of the complex IT environment created inside the dient's company and as a result of diverselT audit softwareand mobile devices that are now 
part of the auditors' daily work. The auditors' thinking and procedures reshaped as a response to the new challenges. Auditing implies a deep understanding of the control environment, more and more IT-based in nowadays, that determine the auditors' decision in regard with the nature and deepness of the tests and procedures applied.

In the last years, the mobile devices and, especially smartphones and tablets, have exceeded the number of laptops and desktops. These mobile devices became significant instruments in the professional and personal life In the business environment, the use of mobile devices and specialized applications offered important benefits as for example: high speed connectivity with the clients and employees, unlimited access to information, a closer collaboration between the actors in the business environment, new products and services delivered, improved and more accurate information provided for the decision making process. The companies that are proactive and prove strategic orientation to the new information technologies face better the competitive challenges and succeed in their effort to grow futureopportunities. "Many technologies considered emerging - likecloud and mobile solutions - are quickly becoming mainstream" (Wolters Kluwer CCH, 2013:10). The professional use of mobile devices, and here is a significant increase of the BYOD (Bring Your Own Device) trend, induces not just significant advantages but also new problems and concerns regarding sensitive data security. Not all the companies proved real awareness regarding data security in the context of BY OD swift. Nowadays it is observed the extended professional use of $m$-devices like tablets and phones in social media. The more active ones are the young professionals. The vast majority prefers to act as "listeners" rather than "contributors" (INSIGHT, 2015). The international surveys emphasize that accountants are using social media aiming at remaining in contact with their professional network, keeping up to date with professional issues and sharing knowledge (idem).

The same trend of integration of the mobile devices it is observed in the educational environment. Next to the elearning concept it is now more referred the concept of m-learning defined as a complementary form of learning, adapted to the digital era, offering direct access to the information with no space and time limit. The opportunities offered by m-learning are useful for the student's formation and also for the live long training of the professionals. The Romanian as well as the southeastern European scientific literature are scarce in regard with mobile use for accounting profession and training. Increased interest on mlearning has been reveal ed by the literature review on the Asian and Anglo-Saxon academic space. In this regard the authors' research provide significant insights ai ming at motivate and stimulate the mobile devices use in the accounting professional life and the academic and long life accounting training. 
The present research is part of a wi der research project initiated fiveyears ago aiming at analysing and tracking the evolution of the accounting profession and the imperative requirements raised by the professi on for the accounting students trai ning through the university studies as a result of the IT deep emerge in the accounting professional life.

The purpose of this paper is to develop a discussion on the IT role and importance for the accounting profession and to raise the awareness on information technology dimension in the field and on the need for a more adequate training, using all new approaches and devices (mobile devices inclusively), in the benefit of the future professionals as well as for the certified accountants and auditors.

\section{Literature review}

\subsection{The accounting reshaping in the digital era}

The constant and sometime unforeseeable evolution of the global society inducing the dynamic of the professions, accounting inclusively, imposes permanent update of the universities' curriculum The professional challenge is significant and the accounting aspirants have to face complex professional requirements. The Association of American Colleges and Universities signall led since2007 that thenew generations of graduates "need a cross-disciplinary knowledge, high level skills, an active sense of personal and social responsibility to apply knowledge to complex problems" (AAC\&U, 2007:3). In this respect, universities cooperate with the professional bodies and recruiting companies ai ming at revise the graduate attributes. As McCabe states, "graduate attributes are the qualities, skills and understandings the university community agrees its students should devel op during their time with theinstitution" (McCabe, 2010: 1). Thosegraduate attributes have to cover technical knowledgespecific for theaccounting profession and a diverse set of skills providing all together the professional basic foundation for the future accountant making him prepared to face not only the present challenges but also to permit its professional devel opment for the next 30-40 working years. The IT skills and knowl edge and the critical thinking are new learning coordinates in our opinion. In this context the universities should find the right answers at least two imperativequestions: (1) What the accounting student should know?; (2) How he should learn? Meaning which are the most appropriate approaches and technical (digital inclusively) means for accounting learning.

The accounting and financial professionals' work is performed today in a highly computerized environment This new professional context implies extended IT abilities and skills for the accountants, changes in their thinking and work methodologies and procedures, new analytical skills and relevant information 
security knowledge. Theentireaccounting professional profile has been changed and this process will continue.

If traditionally, accountants analysed only historical data, nowadays they need to investigate a larger field - big data - and to gain extended skills and knowledge to explore this endless and permanently renewing source of data. "As big data accelerates the process by which business reimagines itself, so the accounting and finance professionals will have to start to reinvent themselves" (Faye, 2013: 8). Information technology in general and big data in particular will reduce the time spend by accountants for collecting, val idating and processing (classical processing) data and enlarge the time spend for anal ytics procedures delivering business insights and stronger risk assessment changing the accountant role inside the company. Nga and Mun consider that the role of the accountant needs to be transformed from the "classical one" to a controller and moving onward as an enabler and co-creator of organizational value (Nga \& Mun, 2013). The future accountants "have to be prepared for a more engaging role as leaders and partners of organizational change" (Nga \& Mun, 2013: 503).

Special ists, clients and business managers positively appreciate the increasing usage of the mobile devices in the business and accounting field. Statistics emphasize that smartphones and tablets sel ling increased significantly from $11.8 \%$ in 2013 to $16.5 \%$ by 2017, and smartphones will increase from $59.5 \%$ to $70.5 \%$ (Columbus, 2013). The mobile workforce registered constant increase as a result of the BYOD wave being estimated at 1.3 billion in 2015.

Peters (2007) appreciates that the usage of the mobile devices in the business environment conducted to increased efficiency by flexibility, speed and access to the information for the businessmen at gl obal scale, an increased satisfaction for their users, improved conditions for data storage and the associated back-up, "saving of time and money and creating greater responsiveness to change" (Peters, 2007: 9).

Today, mobiledevices likesmartphones, tablets, notebooks etc. are vital instruments for the all accounting professionals providing the needed junction between their work and day-by-day life „These technol ogies will reinvent work and the workplace, all owing greater flexi bility around when, where and how work is done. Being onsite will become much less important, and these tools will enable, and often require, anytime, any place work" (INTUIT, 2011: 6). In the same time it can be observed that the decrease of the time needed for accounting and financial data collection and validation has ensured increased analysis opportunities in the benefit of the clients and themobil e devices integration has generated a higher degree of work's flexibility and a moreampleinteraction with theclients. This context of mobiledeviceinsertion in the professional work ensuring connectivity and availability "at anytime and anywhere" raises the potential risk to loose "control over boundaries between work 
and personal activities" (Cousins \& Robey, 2015: 37). This is an important issue that should be researched being a significant gap in regard with the negative and unpredictable impact of mobile devices.

\subsection{M obile devices in the accountants' education and training}

The changes induced by the new information and communication technologies had a significant impact over the education and training systems. It is observed an evolution from the traditional approach to new ones as for example eleaming and m-learning approaches. Nowadays the potential of Internet is exploited by implementing blending learning not only by the universities but al so by special ized training companies, accounting field being one benefiting of the new approach. Blended learning is generally positively perceived by students and ensures timeless access, time saving and induces lower costs of education. There are al so drawbacks, the most important one being the lack of indirect contact with the teacher and, by consequence, being unable to ask questions on regular basis (Grabinski et al., 2015). In the context of e-learning expansion, mlearning became a "natural" step forward. The literature offers a large set of definitions for m-learning. Some authors consider, m-learning as an extension of elearning characterised by the usage of mobile devise. "A new stage of elearning having the ability to learn everywhere at every time through use of mobile and portable devices" (Georgiev et al., 2004 cited by Akour, 2009) or "E-learning that uses mobile devices and wireless transmission” (Pinkwart et al., 2003 cited by Akour, 2009). Some other researches emphasize another important characteristic of m-learning system getting access to the information in any time and location (Kutluch \& Gulmez, 2013, Cheon et al., 2012) hereby maintained the advantages of elearning unanimously appreciated by the students. The arguments for this point of view stay in the mobile device properties: "(a) portability: mobile devices can be taken to different locations, (b) instant connectivity: mobile devices can be used to access a variety of information anytime and anywhere, and (c) context sensitivity: mobile devices can be used to find and gather real or simulated data" (Ben Moussa, 2003; Churchill \& Churchill, 2008; Klopfer et al., 2002; Sharples, 2000, cited by Cheon et al., 2012: 43). Weal so retain the opinion emphasizing that portability, social interactivity, context sensitivity, connectivity and individuality ( $a$ ", unique scaffolding that can be "customized to the individual's path of investigation") "produce unique educational affordances" (Klopfer et al., 2002 cited in Peters, 2007: 3).

Akour (2009) considers technology as a significant component of the mlearning system theinfrastructure, the mobile devices applications' interface, and the quality of the service represent characteristics with significant impact over the m-learning system Aiming at completing the definition of the m-learning paradigmit should be added next to the technical component, the content, the curriculum design, and student learning styles. The mleaming system offers flexibility (the trainee decides 
when and where to study), availability for the persons with diverse disabilities, ensures interactivity by providing an easier cooperation and communi cation between trai nees; stimulate the interest for the studied topics and increasing the efficiency of the learning process. The advantages offered by mlearning facilitates its promotion in the academic teaching process as well as in the accounting professional area aiming at improve live long training. There are also disadvantages induced by the technical characteristics of m-devices: limited memory, small screens, need for battery recharge, loosing Internet connection in the areas with limited access, use of files with special format. M-learning has different parameters comparing with e learning and also t-learming (tablet learning). That imposes the learning materials adaptation in regard with the learning device. Aiming at providing useful learning materials, they have to be adapted "for delivery from " $\mathrm{e}$ " to " $\mathrm{m}$ " and, now, from " $\mathrm{e}$ " to " $\mathrm{t}$ " and from " $\mathrm{m}$ " to " $\mathrm{t}$ " "(Little, 2013: 29). Tablet use in learning purposes is increasingly accepted being also a device used in work environments. The advantages brought by tablets are: light, "easy to transport, and have an interface capable of integrating all inputs and outputs" (Burford \& Park, 2014: 622).

The students' interest for m-devices use in the learning process emphasized that students are "digital natives"; they natively speak the digital language of computers, handheld devices, and the Internet". In opposite, the professors manifested a reticence for the use of mobile devices (Derakhshan, 2009). In this context, the mlearning has the potential to increase thestudents' interest for study and, on theother hand implies the professors special training in this regard so that the learning materials to be adapted to these new requirements.

AI Fahad (2009) studied theK ing Saud Uni versity students' attitudes and perceptions towards the effectiveness of mobile learning. His conclusions underline that the majority of the students, subjects in his study, considered that the wirel ess networks increase the flexibility access to the educational resources and the students' implication in the educational process is al so increased. Al Fahad al so emphasized that students' engagement in the learning process was affected in multiple ways: behavioural, intellectual and emotional. Kutluk and Gülmez (2013) have analysed the mobile leaming perspective in the case of students taking accounting lessons. They retain thestudents' positive attitude in regard with mobile devices' integration in the learning process as a result of the ease of use and flexibility in research and homework tasks.

Several studies emphasize the m-learning disadvantages, analysed from technical, psychological and pedagogical point of view. Technically, the limits are induced by factors like: screen di mension and low resolution, inadequatememory, sl ow network speeds, and lack of standardization and comparability (Haag, 2011; Huan et al., 2008; Lowenthal, 2010; Park, 2011; Wang \& Higgins, 2006; Wang et al., 2009 cited by Cheon et al., 2012). The psychological limitation is exemplified by the hedonic 
use of m-devices such as texting with friends, listening to music, and checking social network services (Park, 2011; Wang et al., 2009 cited Cheon et al., 2012). The students less focus and class disruption induce the pedagogical limitations.

Being registered a gap in the research in regard with the Romanian students' perception on the m-devices use in their training and future professional life, the authors perform an empirical study, the findings and concl usions being synthetized in the chapters below.

\section{Insights in mobile devices perception of R omanian accounting students - An empirical study}

\subsection{M ethodology}

The authors' research had two coordinates: a qual itative one aiming to identify the tendencies, priorities, objectives in accounting profession as a result of the information technology penetration in the companies' processes and accountants' work and a second one ai ming at performing and empirical study in regard with the accounting students preparedness for the professional life in the context of the significant changes imposed by IT impact and especially by mobile devices. The research imposed the literature review of existing studies performed worldwide in regard with the accounting changes and new requirements as a result of the IT impact, and surveys performed by prestigious international organizations regarding the evolution of accounting profession in all its aspects and fields of action. The authors investigated the scientists and academics' research on the topic and retai ned their opinions and concerns that were synthetized in the previous chapters.

The empirical study was performed in 2016 aiming at investigate the accounting students':

- familiarity in regard with mobile devices

- opinion on mobile devices' use for professional purposes

- perception on ethical characteristics of an accounting professional.

Subjects of our study were the students of the Bucharest University of Economic Studies. Wecollected atotal of 110 questionnaires, out of which we discarded seven. In our sample, $67 \%$ of the respondents are bachel ors in Accounting and Management Information Systems and 33\% master students in Accounting and Management Information Systems and Finance and Banking. 85.4\% of the respondents were female, reflecting the characteristic of the students' structure in the Bucharest University of Economic Studies. The questionnaire included 10 items, and we conducted the data anal ysis starting from the fol lowing questions: 
1. Are the accounting students aware of the IT importance for the profession?

2. Are the accounting students familiar with mobile devices use?

3. Do they appreciate the adequacy of mobile devices for the accounting work?

4. What are the usual activities performed on mobile devices by the accounting students?

5. Which are the accountant professional most important characteristics? Thestudy results and conclusions are presented in the chapter below.

\subsection{R esults and discussions}

The study emphasized the students' awareness on the need of mobile devices use in the professional life $92.2 \%$ of the respondents consider very important the use of mobile devices the most appreciated being the laptops followed by tablets, notebooks, iPods and PDAs.

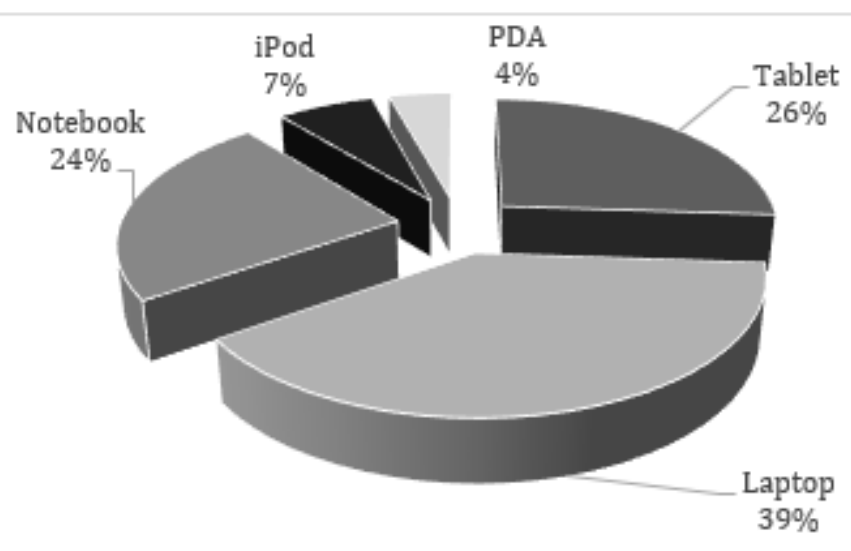

Figure 1. Types of mobile devices used by accounting students

Based on the responses, we conclude that the students are using a diverse set of mobile devices; just 13 out of 103 declared that they are not using mobile devices ( 7 bachel ors and 6 master students). In the top of the respondents' preferences are the laptops and smartphones. We detailed our analysis on the main groups of respondents: undergraduates and master students.

We investigated which are the mobile devices used by the undergraduate students. $44.12 \%$ declared that they are using just laptops, $11.76 \%$ are using smartphones, and just two students are tabl et users. $32.35 \%$ of the undergraduates have in daily use two mobile devices (mainly laptops and smartphones), 10.29\% are using three mobile devices and just one student is using four mobile devices (laptop, 
smartphone, tablet and notebook). Seven students did not mention a mobile device in their daily use, and two-mentioned PCs (device that cannot be ind uded in mobile category).

In the master students' sample, $45 \%$ are laptops' users out of $48.58 \%$ that declared that are using one mobile device $34.28 \%$ are using on daily basis two mobile devices, 6 students out of 35 did not mention a mobile device and 2 master students mentioned PCs as a mobile device.

Table 1. Number of devices used by student

\begin{tabular}{cccccc}
\hline & $\begin{array}{c}\text { 1 mobile } \\
\text { device }\end{array}$ & $\begin{array}{c}\text { 2 mobile } \\
\text { device }\end{array}$ & $\begin{array}{c}\text { 3 mobile } \\
\text { device }\end{array}$ & $\begin{array}{c}\text { 4 mobile } \\
\text { device }\end{array}$ & $\begin{array}{c}\text { No mobile } \\
\text { device }\end{array}$ \\
\hline $\begin{array}{c}\text { Undergra } \\
\text { duates }\end{array}$ & $45.6 \%$ & $32.35 \%$ & $10.29 \%$ & $1.47 \%$ & $10.29 \%$ \\
$\begin{array}{c}\text { Master } \\
\text { students }\end{array}$ & $48.58 \%$ & $34.28 \%$ & 0 & 0 & $17.14 \%$ \\
\hline
\end{tabular}

The responses reveal some important information: the students are mobile devices users in an overwhel ming majority. In the top of preferences, for both undergraduate and master students are the laptops and smartphones. 17 students (16.5\%) out of 107 did not mention a mobile device or indicated PCs. In our opinion, these $16.5 \%$ of the sample don't have a correct understanding of the concept of mobile device. We consider that more detailed training on mobile devices topic is needed aiming at clarifying the m-device concept, the specific characteristics, functionalities, advantages and disadvantages and how these devices can be integrated in the accounting systems and work.

There are mobile devices that are not frequently used as for example tablets, notebooks etc. This situation can be explained in two ways: the students did not feel the need to use these kinds of devices (they are not aware of the devices capabilities or they really don't find these devices useful for their use) or there are financial constraints determining a certain priority in the mobile device purchase. If we correlate thestudents' answers on the use of mobile devices with the ones regarding the purpose of mobile device use, there is an evident correlation. As long as the students are using the mobi le devices for collecting information and communication, the laptops and mobile phones are providing the needed capabilities. That is why, more theoretical and practical study cases are needed ai ming at provide information in regard to them-devices utility and capabilities.

The respondents' use of mobile devices on daily basis aim activities like collecting information (94.68\%), communication (86.17\%), information share $(63.95 \%)$, and collaboration (62.33\%). $32.35 \%$ of the undergraduates and $34.28 \%$ of the master students declared that they spend, daily, the same time for all the above mentioned activities. The fact that collecting information and communication are on the top of 
preferences is not surprising and confirms the results from the authors' surveys on previous graduates' generations. It remains the problem of selecting the information from credible sources, on this topic being room for training improvement. It is encouraging to see that $62.33 \%$ of the respondents consider mobile devices as providing collaboration support. The profession its self imposes collaboration and support for the work group and mobile devices are appropriate in this regard.

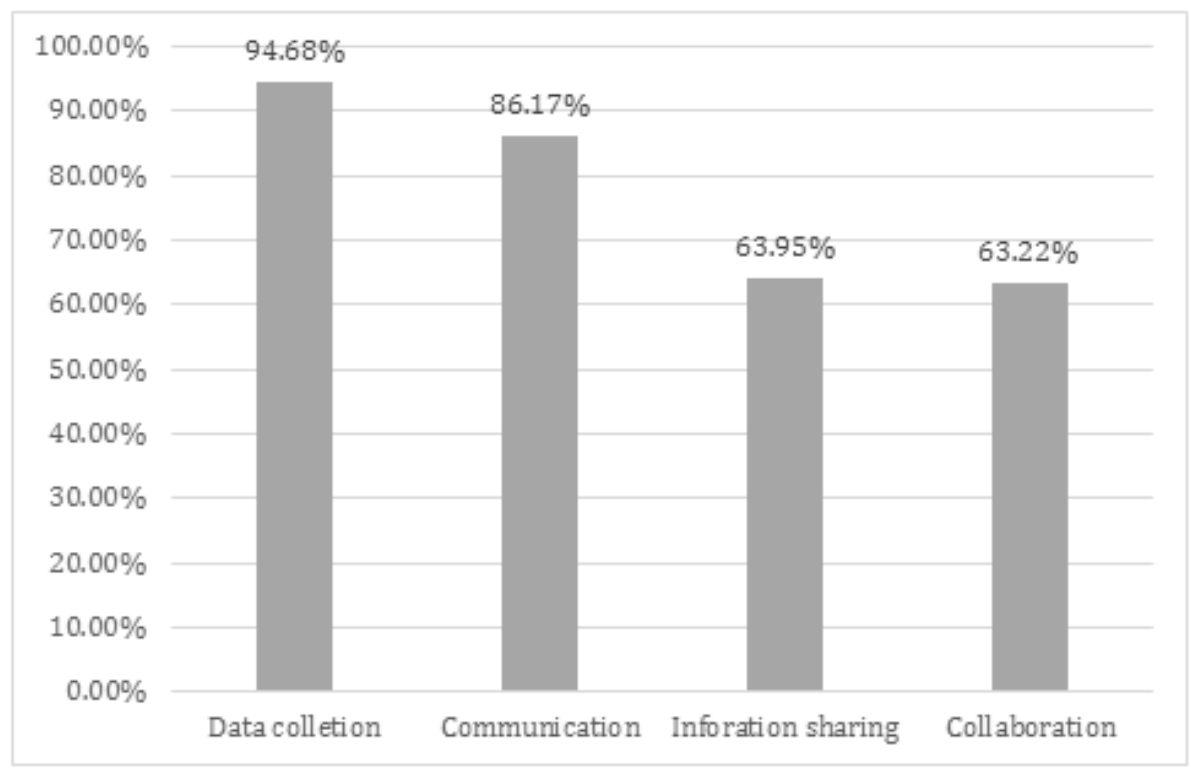

Figure 2. Accounting students' preferences for $m$-devices activities on daily basis

We al so wanted to investigate the students' perception in regard to computing skills needed by the accountants. $96 \%$ of the respondents considered the computing skills as very important and important J ust 2 respondents considered the computing skills as being not important In our opinion, this correct perception of the majority of respondents is sustained by the coherent and well bal anced set of IT courses included in the Faculty of Accounting and Management Information Systems' curriculum The theoretical basis and, very important, the practical abilities and skills acquired in the IT classes, in regard with accounting and auditing issues, determined the students' awareness on IT knowledge related to the profession. This IT fundaments will offer a solid base for further developments and will ensure their proactive approach towards new information technology use in the profession. Being familiar with mobile devices and understanding the advantages brought by these technol ogies, thestudents agreed on the utility of mobile device usein theaccounting profession.

We investigated the students' opinion in regard to the social media use in the accounting profession. $\mathbf{9 7 . 1 7 \%}$ of the respondents recogni sed the social media utility 
for the profession. The main declared scope was to collect professional knowledge (55.34\%). Getting new clients represents the second motivation (34.95\%), and lastly, knowledge share was indicated by $33.98 \%$ of the respondents. Our findings corroborate with previously researches in regard with Romanian accounting students preferences for the use of social networking and the opportunity of their use for the professional developments (Stanciu \& Aleca, 2012). The authors' survey results are also in line with the international surveys on the same topic, indicating a passive attitude (preferring to collect new information and knowledge then sharing ones). These responses are correl ated with the ones reflecting the students' preferences in regard with the mobile use, when they indicated as first preference the information collection.

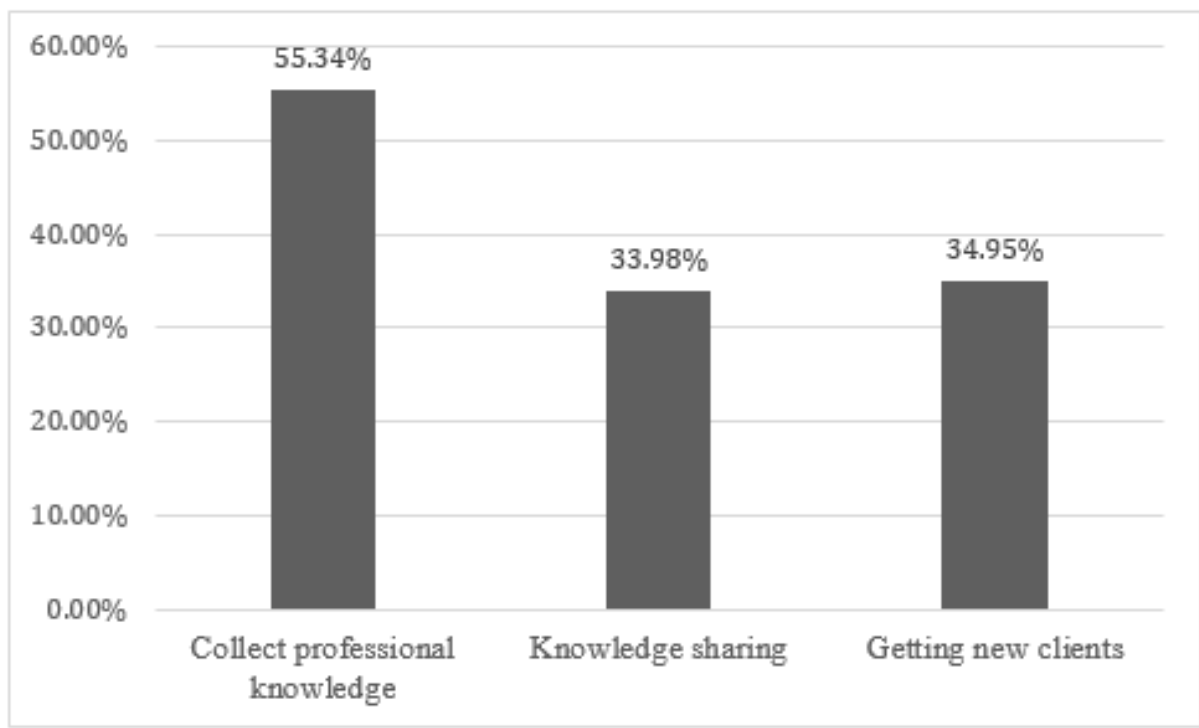

Figure 3. Social media use in profession

We wanted to see the students' perception in regard with mobile devices use in the learning process. The advantages offered by mobile devices analysed were: interactivity, user satisfaction, efficiency, flexibility, and availability for persons with disabilities. The most students' options go to efficiency, interactivity and flexibility (Table2).

Table 2. Students' opinion in regard with the m-devices advantages in the learning process

\begin{tabular}{lrrrrr}
\hline & Interactivity & $\begin{array}{c}\text { User } \\
\text { satisfaction }\end{array}$ & Efficiency & Flexibility & A vailability \\
\hline $\begin{array}{l}\text { Undergra } \\
\text { duates }\end{array}$ & $35.29 \%$ & $7.35 \%$ & $33.82 \%$ & $22.06 \%$ & $1.47 \%$ \\
Master students & $25.71 \%$ & $2.86 \%$ & $51.43 \%$ & $14.29 \%$ & $5.71 \%$ \\
\hline
\end{tabular}


Taking into consideration the survey's targeted subjects, undergraduates in the 3rd year of study and master students, weinvestigated which are, from theirs perspective, the most important characteristics for an accountant. Our analysis was performed on three layers: ethics (with the following characteristics: honesty, integrity, trustworthy), professionalism (with the characteristics: professional, intelligent, wise, specific abilities) and leadership (with the characteristics: charismatic, model for others, good communicator, good listener, good organizer, high influential). On ethical layer integrity and honesty werethemost appreciated. On the professionalism layer, the accountant professional profileand his intel ligence were most appreciated. Less importance was al located to wisdom and specific abilities. We believe that the respondents' limited experiencein professional lifeexplains their options; as long as for example wisdom is a characteristic that usually is put in relation with mature generation. In the respondents' view an accounting leader should be a good organizer, demonstrating good communication skills and being a good listener. His power of influence is appreciated to be more important rather than his abi lity to bea model for others and his charisma.
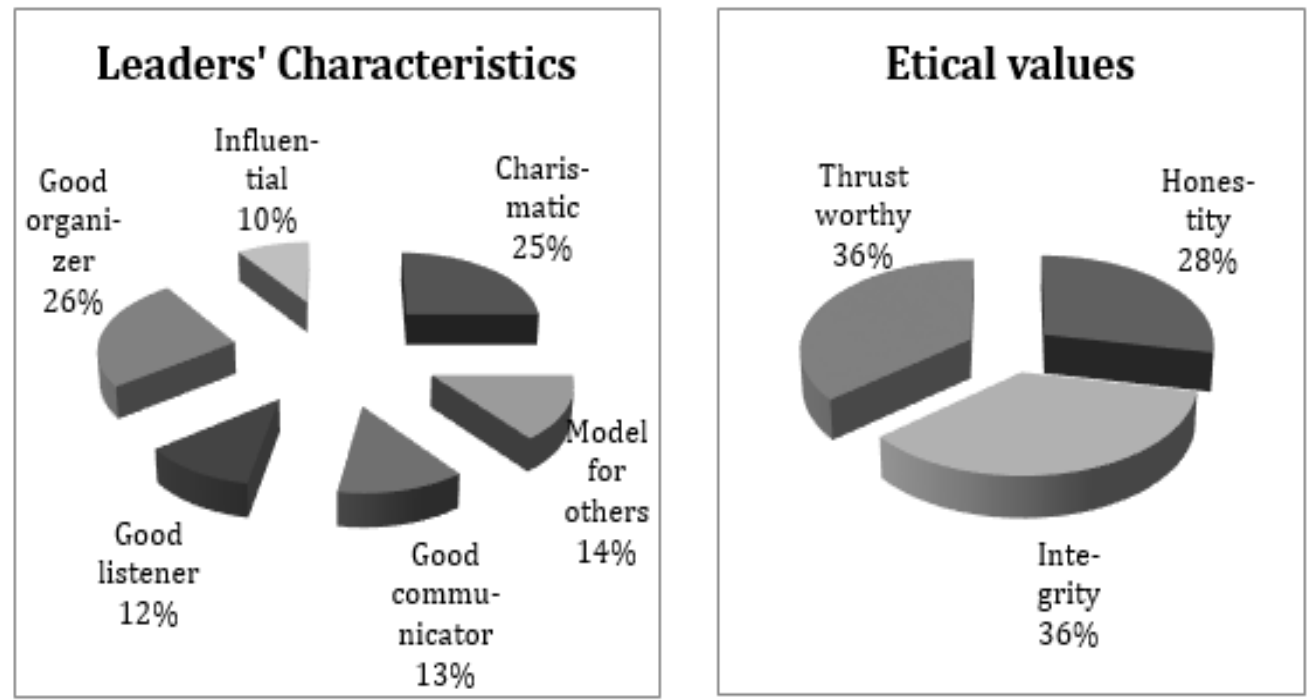

Figure 4. Students' perception on the accountant characteristics

The data anal ysis emphasizes that on the professional ism layer the most appreciated characteristics by the undergraduates and master students were professional and intelligent and for the leadership layer: good organizer and good communicator (figure no. 5). 


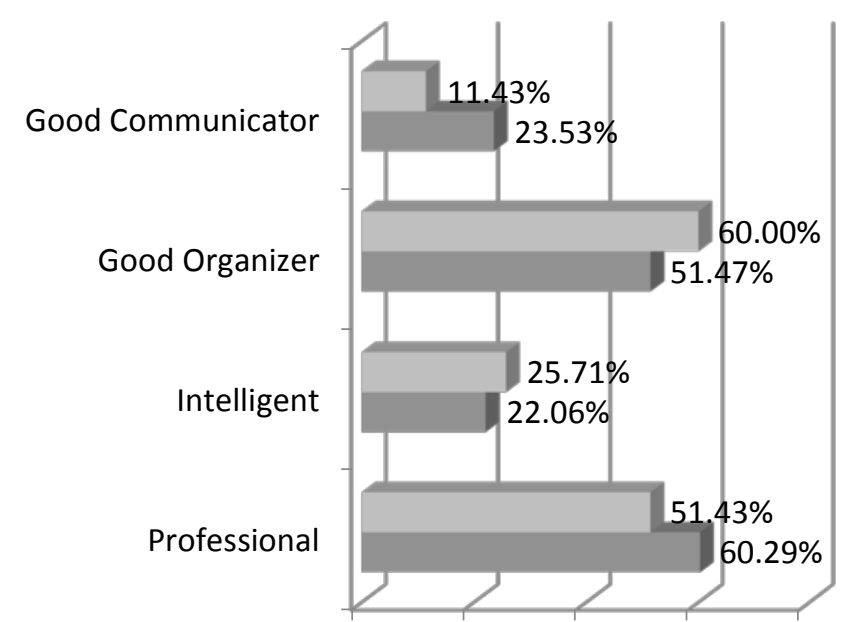

Master Students

- Undergraduates

$0.00 \% \quad 20.00 \% 40.00 \% 60.00 \% 80.00 \%$

Figure 5. Students' perception on the chief accountant profile

The graphic shows that the respondents (both the undergraduates and master students) correlate the professional characteristic with that of good organizer for the accounting leader.

Or the ethical layer there are differences in the subjects' opinions: the most appreciate by the undergraduates ( $54.41 \%$ ) is honesty and by the master students the trustworthy (42.86\%).

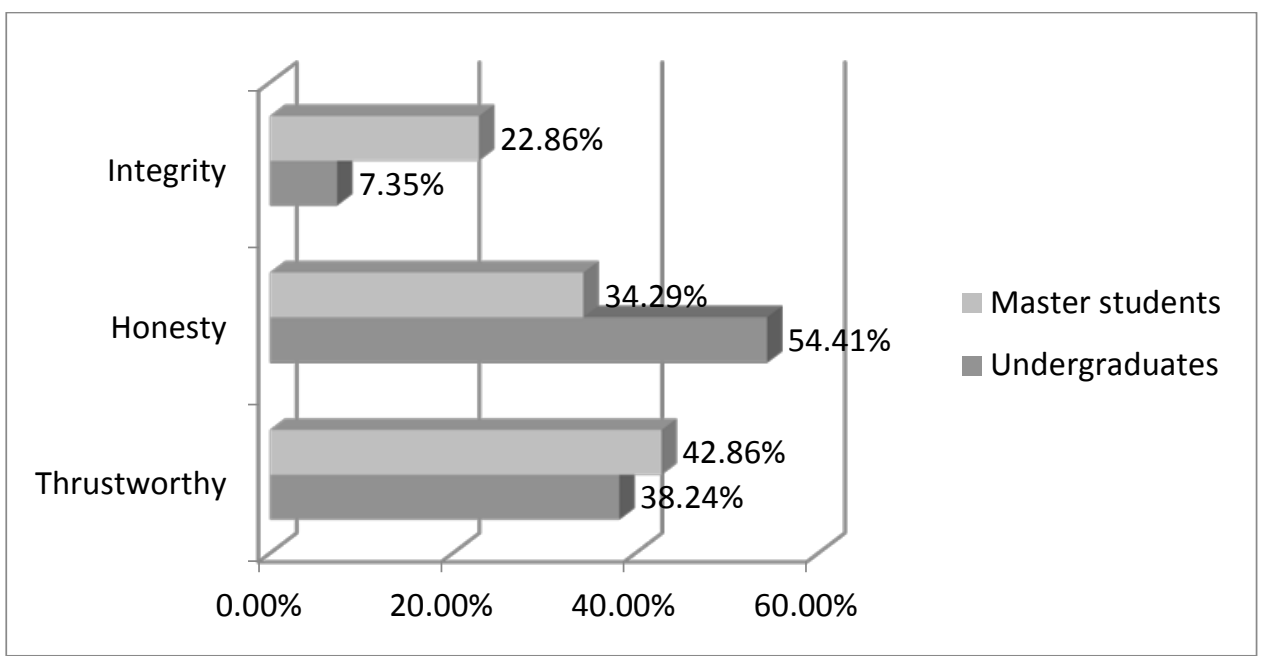

Figure 6. The respondents' opinion on the most important ethic characteristics 
It was very important for us to see the undergraduates desire to apply for an accountant position. 66 out of 68 Accounting and Management Information Systems undergraduate students declared they option for an accounting career. One respondent declared that he wishes to apply for a programmer position (this being in linewith thefacul ty speciality- Accounting and Management I nformation Systems). J ust one undergraduate declared that the accounting profession is not in linewith his profile and, as a consequence, he is going to change the professional path.

Following the questions representing theinitial starting point of our investigation the authors can conclude that:

- The students are aware of the importance of IT knowledge for the profession and consider mobile devices useful for their future work;

- The students are daily users of laptops and smartphones, and less oriented towards tablets and notebooks.

- There is room for better training in regard to the mobile devices capabilities aiming to enlarge their use for more diverse activities in accounting activities.

- Social media is consi dered important for the profession but the students prefer a passive role.

- Mobile devices use in training and learning is appreciated for the flexibility and efficiency provided.

\section{Conclusions}

The accounting profession continues its renewal facing the IT wave aiming at remaining in line with the companies' and society requirements. This process is continuous and implies deep changes in the accounting professionals' profile and work. New skills, knowledge and abil lities are required nowadays. The accountants' work, in all the areas of the profession, is changing not only at the level of means and techniques used but also in its content and role. New developments like cloud computing, big data, mobile devices are impacting the accountants' work and way of thinking. The hugestream of data, which is increasing day-by-day, shoul d be well managed, store, processed and secured and the accountants have to adapt their work to the new IT environment. The changes in the accountant work determine a significant swift in regard with the accountant role in the company. He is now more implied in planning and strategic tasks and is a partner of organizational change.

The attention provided to the mobile devices is sustained by the significant advantages: flexibility, connectivity, portability, and ease of use The other side of the coin emphasizes important concerns in regard with data security and the risk to lose control over boundaries between work and personal activities. Strong security and data processing pol icies next to improved organizations' cultureand empl oyees' 
training will facilitatetheright integration of mobile devices in the accountants work and training, making possi blethemaximization of theIT resources effectiveness and efficiency. The authors' research emphasized the Romanian accounting students awareness in regard with the utility of the m-devices in the profession and their "native" ability in m-devices' use. Their preferences in regard with m-devices use are centred on communication and data collection. Social media represents one of the most important coordinates in the students' daily m-devices' use Social media is perceived as very important for the professional life facilitating knowledge acquisition and providing visibility in the professional life and, by consequence, increasing the chance to enlarge the client portfolio.

The authors' research covers an area less investigated in the Romanian and south eastern Europe and fills a gap in the Romanian literature in regard with this topic. The purpose of this paper was to devel op a discussion on the IT role and importance for the accounting profession and to raise the awareness on the mobile devices use in the benefit of the accounting professionals work and training.

\section{Acknowledgements}

The paper was presented in the 12th International Conference Accounting and Management Information Systems AMIS 2017, Bucharest, Romania and the authors benefited of the debates and recommendations of the partici pants. The present paper integrates the recommendations and feed backs of the special ists partici pating to the conference.

\section{R eferences}

AAC\&U (2007) "College Learning for the New Global Century. A report from the National Leadership Council for Liberal Education \& America's Promise", available on-line at https://www.aacu.org/sites/default/files/files/LEAP /GlobalCentury_final.pdf

Akour, H. (2009) "Determinants of mobile learning acceptance An empirical investigation in higher education" (Doctoral dissertation), availableon-line at https://shareok.org/bitstream/handle/11244/7764.

Al-Fahad, F. N. (2009) "Students' attitudes and perceptions towards the effectiveness of mobile learning in King Saud University, Saudi Arabia", The Turkish Online J ournal of Educational Technology, vol. 8(2), available on-line at http://www.tojet.net/articles/v8i2/8210.pdf.

Burfors, S. \& Park, S. (2014) "The impact of mobile tablet devices on human information behaviour". J ournal of Documentation, vol. 70, no. 4: 622-639

Cheon, J, Lee, S., Crooks, S. M. \& Song, J. (2012) "An investigation of mobile learning readiness in higher education based on the theory of planned behaviour". Computers \& Education, no.59: 1054-1064 
Columbus L, (2013) "IDC: 87\% of Connected Devices Sales by 2017 Will Be Tablets and Smartphones", available on-line at http://www.forbes.com/sites/ louiscolumbus/2013/idc-87-of-connected-devices-by-2017-will-be-tabletsand-smartphones.

Cousins, K. \& Robey, D. (2015) "Managing work-life boundaries with mobile technologies. An interpretative study of mobile work practice", Information Technol ogy and People, vol. 28, no. 1: 34-71

Derakhshan, N. (2009) "Student and faculty perceptions of the features of mobile learning management systems in the context of higher education" (Doctoral dissertation), available on-line at http:shareok.org/bitstream/handle /11244/9739/ Derakhshan okstate

Faye, C. (2013) "Big data: its power and perils", ACCA, November 2013, available on-line at www.acca.org.

Grabinski, K., Kedzior, M. \& Krasodomska, J . (2015) “Blended learning in tertiary accounting education in the CEE region - A Polish perspective", Accounting and Management Information Systems, vol. 14, no. 2: 378-397

INSIGHT (2015) "Wolters Kluwer 2015 Social media survey - How Accountants are using social media for marketing and promotion", available on-line at www.cc.Co.uk

INTUIT (2011) "Intuit 2020 Report Future of the Accounting Profession. A New Mind set and Model for Thriving in a Connected World", avail lable on-line at http://http-download.intuit.com/http.intuit/CMO/intuit/futureofsmall business/intuit_corp_vision2020_0111v5.pdf.

Little, B. (2013) "Issues in mobile learning technology", Human Resource Management International Digest, vol.21, no. 3: 26-29

Kutluk, F. A. \& Gülmez M. (2013) "A research about mobile learning perspectives of university students who have accounting lessons", Procedia - Social and Behavioral Sciences, no. 116, available on-line at http://www.sciencedirect.com/science/article/pii/

McCabe, G. (2010) "Graduate attributes and empl oyability hel ping universities and students for the changing landscape", Interchange Spring, avail lableon-line at www. Tla.ed.ac.UK/interchange

Nga, J., Mun, S.W. (2013) "The perception of the undergraduate students towards accountants and the role of accountants in driving organizational change. $A$ case of study of a Mal aysian business school", Education + Training, vol. 55, no. 6: 500-519

Peters, K. (2007) "m-Learning: Positioning educators for a mobile, connected future", International Review of Research in Open and Distance Learning, vol. 8, no. 2

Stanciu, A. \& Aleca, O. (2012) "Social networking as an al ternative environment for education", Accounting and Management Information Systems, vol. 11, no. 1: 56-75

Wolters Klucer CCH (2013) "CPA Firms succeeding in thenew economy", avai lable on-line at CCHGroup.com/Leaders. 